\title{
Pleomorphic Adenoma of the Parotid Gland: A Case Report
}

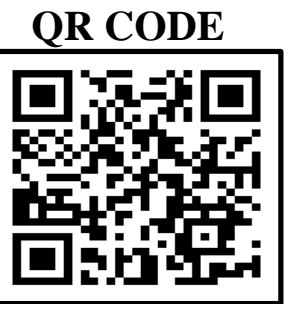

\section{RAJESH GUPTA*1, PREETY GUPTA², SHIVANI GUPTA³, SUMIT GARG ${ }^{4}$}

Salivary organ tumors are uncommon, including under $3 \%$ of all neoplasia of head and neck district. Pleomorphic adenoma is the most well-known salivary organ tumor, representing $60-80 \%$ of amiable tumors of salivary organs. Generally they are found as singular one-sided, firm and portable, effortless, moderate developing mass. The board includes careful resection by shallow or absolute parotidectomy.

KEYWORDS: Benign Tumor, Pleomorphic Adenoma, Parotidectomy

\section{INTRODUCTION}

About $70 \%$ of all salivary organ tumors emerge in the parotid organ, and around $85 \%$ are favorable. Pleomorphic adenoma (PA) addresses $45-74 \%$ of all salivary organ tumors and $65 \%$ of them happen in the parotid gland. ${ }^{1-3}$ PA presents clinically as an easy, moderate developing mass, generally differing from 2$6 \mathrm{~cm}$ when resected. ${ }^{4}$ Cases of monster PA have been accounted for in the parotid organ, introducing as an unpredictable multinodular mass that can gauge more than $8 \mathrm{~kg}$. ${ }^{1}$ Most instances of goliath PA were seen before 1980 's, yet a few cases have been distributed recently. ${ }^{4-5}$ These strange cases are treated by parotidectomy, however the chance of positive careful edges and dangerous changes should be thought of. This paper depicts an instance of a goliath pleomorphic adenoma emerging in the parotid organ and treated by absolute parotidectomy with facial nerve safeguarding.

\section{CASE REPORT}

A man aged 45 years presented a complaint of a tumor on the right side of the face for more than 10 years. The patient's history dated back to 10 years when patient noticed swelling on left side of his face. Swelling was small in size earlier and growed gradually to attain its present size. The mouth opening was reduced since 1 month. He had taken some medications for swelling but there was no relief. The nature of medication taken was not known to the patient. He was referred to the dental college for treatment. Patient did not give any history of previous dental treatment. Patient is married and has one child. All the family members were apparently healthy and do not suffer from any related illness. Patient was of moderate built and moderately nourished with normal gait and posture. Patient was well oriented to time, place and surroundings. Patient was calm and quiet and answered to all questions and his eyes to hand coordination were good. Face of the patient was asymmetrical with swelling on left side of his face. Upon extra oral examination, a solitary oval shaped swelling measuring approximately $4 \times 5 \mathrm{~cm}$ in size was observed on the left side of the face extending superiorly from tragus of the left ear to $1 \mathrm{~cm}$ below the angle of the mandible inferiorly and anteriorly from 4 $\mathrm{cm}$ in front of tragus of left ear to the posterior border of ramus of mandible. The left ear lobule was raised. The colour of the overlying skin was same as that of adjacent skin. The margins of the swelling were well defined. No visible pulsations; sinus or discharge of pus or bleeding were seen. A slight reduction in the mouth opening was noted. The overlying skin had same temperature as that of adjacent skin. The swelling was found to be firm along with being slightly tender, nonfluctuant, non-compressible, non-reducible, nonpulsatile in nature and was not fixed to the underlying structures (figure 1).

Gingiva around 37 and 38 region was firm and non tender upon intraoral examination. The teeth in the affected area were sensitive to percussion but no mobility could be demonstrated. Based on clinical examination a diagnosis of pleomorphic adenoma of parotid gland was given.

On further investigations, a panoramic radiograph 


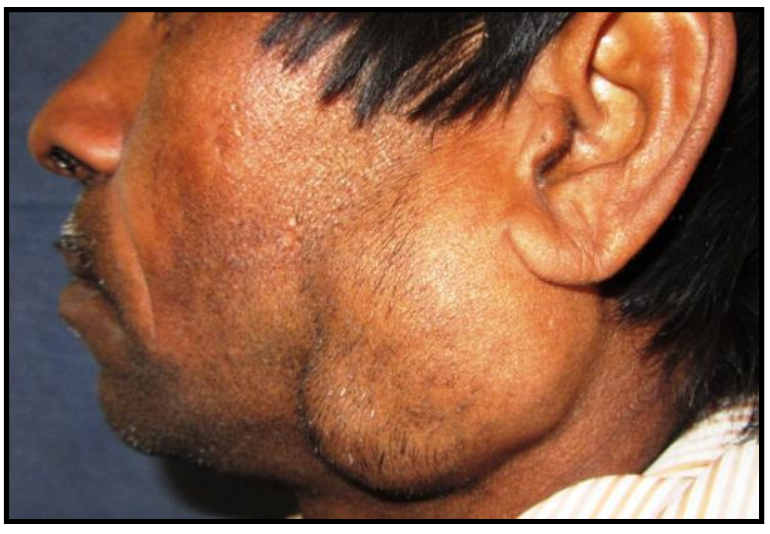

Figure 1. Image of left lateral view of face showing lesion of pleomorphic adenoma

revealed partially edentulous maxilla w.r.t 26 and partially edentulous mandible along with root stumps w.r.t. 16, 17, 28, 37 and generalized bone loss. No other significant findings were observed (figure 2).

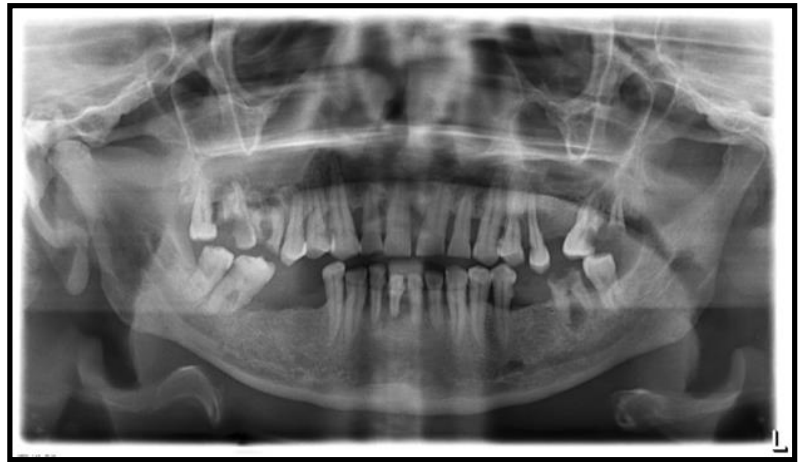

Figure 2. Panoramic image

CT Scan: The antero inferior part of the left parotid gland was extending more anteriorly in a well-defined encapsulated homogeneously hypodense soft tissue swelling of size $3.3 \mathrm{~cm}(\mathrm{ML}) \mathrm{X}_{5} .6 \mathrm{~cm}(\mathrm{AP}) \mathrm{X}_{4.4 \mathrm{~cm}(\mathrm{SI})}$ in the superficial lobe of parotid gland. It was extending into the soft tissue of cheek. The left masseter muscle could not be visualized separately from the mass. The deep lobe of the parotid gland, major vessels appeared normal with no extension of the mass seen into surrounding tissues. The CT scan also reported no destruction of mandible (Figure 3 ).

Histopathological examination revealed epithelial tumor cells arranged in the form of sheets and duct like pattern surrounded by fibrous capsule. The duct like spaces contained eosinophillic coagulum. The connective tissue stroma showed vessels and areas of haemorrhage. A chondroid metaplasia and highly

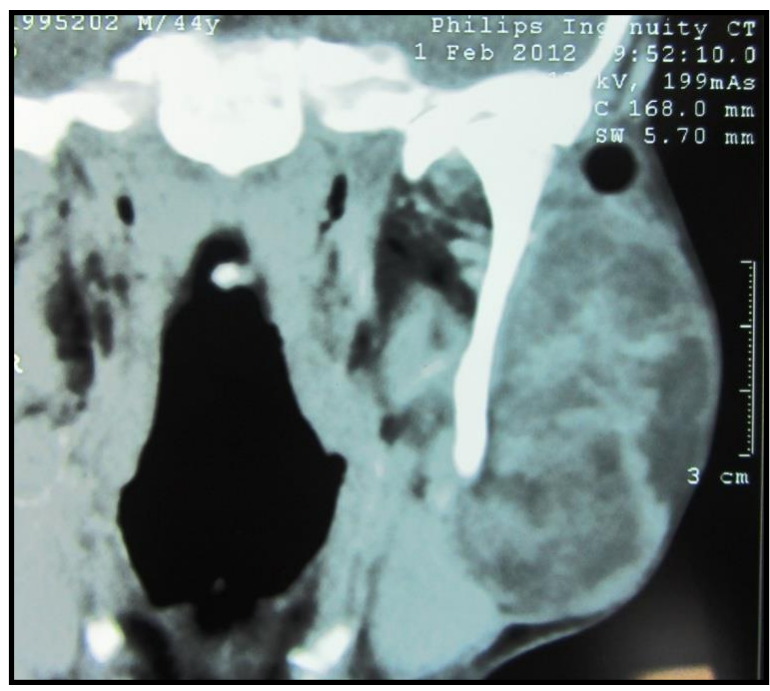

Figure 3. CT Scan

cellular areas were observed. These features were suggestive of pleomorphic adenoma (figure 4).

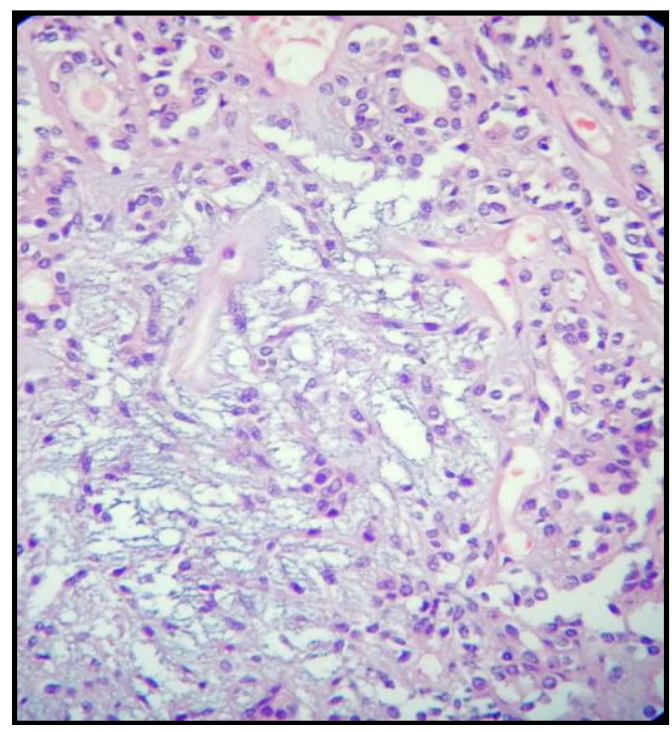

Figure 4. $\mathrm{H}$ and $\mathrm{E}$ stained section in higher magnification showing typical features of a pleomorphic adenoma including islands and strands of epithelium in a myxoid stroma

\section{TREATMENT}

Under general anesthesia, a right total parotidectomy with preservation of the facial nerve and complete removal of the tumor en bloc was done. The postoperative course was uneventful. Macroscopically, the mass was measured $28 \mathrm{~cm} \times 20 \mathrm{~cm} \times 16 \mathrm{~cm}$, and weighed $4.0 \mathrm{Kg}$. Microscopically the tumor was composed of islands and strands of epithelial cells 
immersed in a hyaline stroma, some showing squamous differentiation.

\section{DISCUSSION}

Pleomorphic adenoma is the most well-known salivary organ tumor with parotid organ being the most wellknown influenced site. The ordinary parotid tumor is found beneath the lobule of the ear and overlying the point of the mandible. On net discovering, pleomorphic adenoma is a solitary, firm, versatile, well circumscribed mass. The tumor might be whitish-tan to dark to somewhat blue in shading. It might shift from a couple of millimetres to few centimetres or even to goliath size. They are unpredictably formed ${ }^{1,2}$ and have a bosselated surface. Usually they are found as lone, one-sided, firm and versatile, moderate growing asymptomatic mass. ${ }^{1,2}$ Manifestations and signs rely upon the area. At the point when the tumor happens in the parotid organ, indications of facial nerve shortcoming are only from time to time experienced; in enormous ignored tumors, facial nerve shortcoming is probably going to emerge as the consequence of a dangerous change. Minutely, PAs are described by a heap of morphological variety. Epithelial cells are organized in sheets and islands showing ordinary ductal structures, and different epithelial and myoepithelial qualities as axle, clear, squamous, basaloid, plasmacytoid, oncocytic and sebaceous. The stroma typically is blended, with sinewy, chondroid, mixoyd or hyaline aspects. ${ }^{6,7}$

The present case was framed dominatingly by cuboidal and spindled cells installed in a hyaline and myxoid stroma. The frequency of dangerous change in PAs goes from $1.9 \%$ to $23.3 \% .^{8}$ The exemplary clinical history of carcinoma ex-pleomorphic adenoma is of a sluggish developing mass for a long time, with a new quick growth. An instance of a goliath PA with harmful change with this run of the mill history was as of late revealed by Honda et al. (2005) 5 in a 72-year-elderly person with a lethargic developing parotid injury for a very long time, with a fast expansion over the most recent 3 months. Schultz-Coulon $(1989)^{6}$ detailed 31 instances of goliath PAs and in 3 cases harmful regions were found inside the tumor. Our patient introduced each one of the qualities for an expanded danger of threat, anyway either clinically and minutely there were no such confirmations. The treatment of decision for PAs of the parotid organ is shallow parotidectomy with safeguarding of the facial nerve. In the late instances of monster PA revealed in the writing, the resection of the tumors were performed with conservation of the facial nerve.

\section{CONCLUSION}

Pleomorphic adenomas are benign tumors and most commonly involve parotid gland. Proper diagnosis and careful surgical resection with preservation of facial nerve, helps in better prognosis with least chances of recurrence.

\section{REFERENCES}

1. Eveson JW, Cawson RA. Salivary gland tumours. A review of 2410 cases with particular reference to histological types, site, age and sex distribution. J Pathol. 1985;146:51-8.

2. Alphs HH, Eisele DW, Westra WH. The role of fine needle aspiration in the evaluation of parotid masses.Curr Opin Otolaryngol Head Neck Surg. 2006;14(2):62-6.

3. Atabo A, Bradley PJ. Management principles of head and neck cancers during pregnancy: a review and case series. Oral Oncol. 20o8, 44(3):236-41.

4. Seifert G. Oralpathologie I. Pathologie der Speicheldrüsen. Springer Verlag Berlin 1996.

5. Honda T, Yamamoto Y, Isago T, et al. Giant pleomorphic adenoma of the parotid gland with malignant transformation. Ann Plast Surg. 2005;55:524-7.

6. Schultz-Coulon HJ. Pleomorphic giant adenomas of the parotid gland. Laryngorhinootologie 1989;68(8):445-9. https://doi.org/10.1055/s-2007998373

7. Nasser SM, Faquin WC, Dayal Y. Expression of androgen, estrogen, and progesterone receptors in salivary gland tumors. Frequent expression of androgen receptor in a subset of malignant salivary gland tumors. Am J Clin Pathol. 2003;119(6):801-6.

8. Larbcharoensub N, Cert PK, Tungkeeratichai J, Prakunhungsit S, Narkwong L, Leopairut J. Expression of hormonal receptor in patients with metastasizing pleomorphic adenoma of the major salivary gland; a clinicopathological report of three cases. J Med Assoc Thai. 2009, 92(9):1250-5. 


\section{Cite this article as:}

Gupta R, Gupta P, Gupta S, Garg S. Pleomorphic Adenoma of the Parotid Gland: A Case Report. Int Healthc Res J. 2021;5(3):CR6-CR9. https://doi.org/10.26440/IHRJ/0503.06430

\section{AUTHOR AFFILIATIONS: ( ${ }^{*}$ Corresponding Author)}

1. Reader, Department of Oral Medicine and Radiology, Swami Devi Dyal Hospital \& Dental College, Barwala, India

2. Reader, Department of Public Health Dentistry, Swami Devi Dyal Hospital \& Dental College, Barwala, India

3. Senior Lecturer, Department of Pedodontics, Guru Nanak Dev Dental College \& Research Institute, Sunam, India

4. Senior Lecturer, Department of Periodontics, Guru Nanak Dev Dental College \& Research Institute, Sunam, India 